\title{
Study of the importance of family screening of glaucoma: identifying the target
}

\author{
N Pandey A. ${ }^{1}$, Singh P. ${ }^{2 *}$ \\ DOI: https://doi.org/10.17511/jooo.2020.i03.01 \\ ${ }^{1}$ Achyut N Pandey, Associate Professor, Department of Ophthalmology, Veer Chandra Singh Garhwali Govt. Institute of Medical Science \& \\ Research, Garhwal, Uttarakhand, India. \\ 2* Parul Singh, Associate Professor, Department of Ophthalmology, Government Medical College, Badaun, Uttar Pradesh, India.
}

\begin{abstract}
Aim: To describe the value and results of family screening of glaucoma patients in the glaucoma clinic of a tertiary center in the Garhwal Himalayan region over a period of one year. Material and Method: 300 patients underwent comprehensive ophthalmic examination and glaucoma examination including IOP measurement by Goldman applanation tonometry, binocular dilated fundoscopy with +90D Volk lens, gonioscopy using the 4 mirror Volk goniolens. Results: 300 persons detected with primary glaucoma whose families were invited to participate in the family screening initiative, there were 114 first degree relatives who attended the screening with a response rate of $32 \%$. The relatives of probands ranged in age from 18 to 89 years with $56.8 \%$ being males. 198 were diagnosed as primary angle-closure suspects, 8 as angle-closure,238 as glaucoma suspects and 132 subjects (11.6\%) had definite glaucoma. Most affected subjects were in 40-70 years. The angle-closure disease was found more in females. Conclusion: Study also found a higher prevalence of glaucoma in siblings; especially the angle-closure entity. Targeting first degree relatives of persons with primary glaucoma may offer a relatively inexpensive way of detecting glaucoma and in the identification of suspects at risk of glaucoma who may be advocated closer monitoring.
\end{abstract}

Keywords: Glaucoma, Ophthalmic examination, Visual loss

Corresponding Author

Parul Singh, Associate Professor, Department of Ophthalmology, Government Medical College, Badaun, Uttar Pradesh, India. Email: parulophtha@gmail.com
How to Cite this Article

Pandey AN, Singh P. Study of the importance of family screening of glaucoma: identifying the target. Trop J Ophthalmol Otolaryngol. 2020;5(3):63-65. Available From

https://opthalmology.medresearch.in/index.php/jooo /article/view/121
To Browse

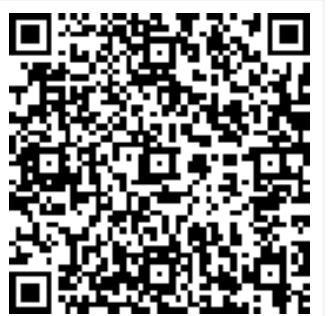

Manuscript Received 2020-03-10

Conflict of Interest No

Review Round 1
2020-03-20
Funding
Nil

(C) 2020 by Achyut N Pandey, Parul Singh and Published by Siddharth Health Research and Social Welfare Society. This is an Open Access article licensed under a Creative Commons Attribution 4.0 International License https://creativecommons.org/licenses/by/4.0/ unported [CC BY 4.0].

\section{Review Round 3}

Review Round 2 2020-03-25

Ethical Approval Yes
Accepted 2020-03-30

Note 


\section{Introduction}

Glaucoma is the leading cause of irreversible blindness worldwide and in India. It has been estimated that nearly 12 million Indians currently have glaucoma and this figure will increase to more than 16 million by the year 2020 [1]. Populationbased studies in India suggest that more than $90 \%$ of glaucoma cases in India remain undiagnosed $[2,3]$. These high rates of undiagnosed glaucoma translate into significant rates of glaucoma blindness.

Since visual loss from glaucoma is preventable if detected and treated early, it is imperative to have population screening. The multiple factors responsible for glaucoma, the multiple tests used to diagnose glaucoma and the low prevalence demand targeted screening of high-risk subgroups. The increased risk of glaucoma in family members of persons with glaucoma has been well recognized. Epidemiologic data from the Baltimore Eye Survey 4 confirm that a family history of glaucoma is an important risk factor. Cross-sectional studies seem to suggest close to $50 \%$ of all glaucomas to be familial and a positive family history confers a threefold increase in the risk of developing openangle glaucoma $[4,5]$.

\section{Aim}

To describe the value and results of opportunistic family screening of glaucoma patients in the glaucoma clinic of a tertiary medical college.

\section{Materials and Methods}

Setting: This study recruited individuals of primary open-angle glaucoma and primary angle-closure glaucoma diagnosed at the glaucoma services in a tertiary center in the Garhwal Himalayan region.

Duration: Study conducted over a period of one year and their families who were invited to participate in the screening program after obtaining informed consent.

Ethical consideration: The family study was approved by the Institutional Review Board and Ethics Committee of the concerned hospitals and was conducted in accordance with the relevant declaration of Helsinki specifications.

Sampling methods: All consecutive persons with newly diagnosed primary glaucoma in the study period were explained about the glaucoma family
Screening initiative by a study coordinator and requested to provide the name, age, sex, nature of relationship and mailing address of their first degree relatives. Informed consent was obtained from all probands to contact their first degree relatives to invite them to participate in the screening to detect glaucoma. The patients were shown a video film and given a brochure emphasizing family screening.

The subjects underwent a comprehensive ophthalmic examination and glaucoma examination including IOP measurement by Goldman applanation tonometry, binocular dilated fundoscopy with $+90 \mathrm{D}$ Volk lens, gonioscopy using the 4 mirror Volk goniolens. The present study included for analysis only the family members who were subject to a complete ophthalmologic evaluation by the study team to confirm or exclude glaucoma. The family members were divided as Type I (Parents/children) or Type II (siblings).

Data analysis: Statistical analysis was done by statistical software STATA 11.0. Chi-square test, independent $\mathrm{t}$-test and paired t-test used. A P-value of less than 0.05 considered statistically significant.

\section{Results}

Of the 300 persons detected with primary glaucoma whose families were invited to participate in the family screening initiative, there were 114 first degree relatives who attended the screening with a response rate of $32 \%$. The relatives of probands ranged in age from 18 to 89 years (Mean $54.85 \pm$ 10.2 years) with $56.8 \%$ being males. Out of 114 subjects screened; 198 were diagnosed as primary angle-closure suspects, 8 as angle-closure,238 as glaucoma suspects and 132 subjects(11.6\%) had definite glaucoma. Most affected subjects were in 40-70 yrs. The angle-closure disease was found more in females. Also, a better review followup of the primary patient and family members was noted $(95 \%)$.

Table-1: Distribution of glaucoma in family members

\begin{tabular}{|c|c|c|c|c|}
\hline \multirow[t]{2}{*}{ Glaucoma } & \multicolumn{2}{|c|}{ Relatives } & \multirow{2}{*}{$\begin{array}{c}\text { Total } \\
(n=1141)\end{array}$} & \multirow{2}{*}{ value } \\
\hline & Type I & Type II & & \\
\hline Open Angle glaucoma & $\begin{array}{l}4.73 \% \\
(54)\end{array}$ & $6.5 \%(74)$ & 128 & 0.993 \\
\hline Angle Closure glaucoma & $0.1 \%(1)$ & $0.3 \%(3)$ & 4 & $<0.05$ \\
\hline $\begin{array}{l}\text { Angle closure } \\
\text { suspect/disease }\end{array}$ & $6.7 \%(76)$ & $\begin{array}{l}14.6 \% \\
(167)\end{array}$ & 243 & $<0.001$ \\
\hline
\end{tabular}




\begin{tabular}{|l|l|l|l|l|}
\hline Glaucoma suspect & $9 \%(103)$ & $11.8 \%(135)$ & 238 & 0.036 \\
\hline Normal & $26.8 \%(306)$ & $19.45 \%(222)$ & 528 & 0.04 \\
\hline
\end{tabular}

\section{Discussion}

Prior studies have indicated that primary open-angle glaucoma is more likely to affect persons with a family history of the disease and positive family history has been assumed to be associated with a significant risk of glaucoma $[5,6,7]$. The Rotterdam eye study had reported a $10 \%$ prevalence of glaucoma in siblings as against $1.1 \%$ in off-springs of persons with glaucoma [8]. Nguyen et al had also reported that siblings among the first degree relatives have the highest risk of glaucoma $[9,10]$. Roughly one in four siblings of Indian angle-closure patients was found to have the angle closure. A study by Sharma et al observed in their study that a total of 514 first degree relatives of 346 persons with primary open-angle glaucoma, of 4972 individuals who were invited to participate attended the screening examination (Response Rate 7\%). Fifty-five percent of those who attended were males and the mean age of participants was 56.8 years. Sixty-eight relatives ( $13.3 \%$ of those screened) were detected to have definite glaucoma. Sixty percent of those detected with definite glaucoma were siblings. Fifteen percent of siblings, $4 \%$ of offsprings and $20 \%$ of parents who attended the screening examination had definite open-angle glaucoma [11]. The present study also found a higher prevalence of glaucoma in siblings; especially the angle-closure entity. The current study found a higher prevalence of definite glaucoma in this cohort than in a general population. Very few published Indian studies are available on family screening of glaucoma. Targeting first degree relatives of persons with primary glaucoma may offer a relatively inexpensive way of detecting glaucoma and in the identification of suspects at risk of glaucoma who may be advocated closer monitoring. Additionally, screening at-risk population benefits in terms of glaucoma awareness, better follow-up and also increase in outpatient clinic volume.

Limitations- Although the study includes 300 subjects, still more can be recruited for the study along with the duration of the study which can be increased.

\section{Conclusion}

There is a higher prevalence of definite glaucoma in this cohort than in a general population.
Very few published Indian studies are available on family screening of glaucoma.

\section{What does the study add to the existing knowledge?}

Additionally, screening at-risk population benefits in terms of glaucoma awareness, better follow-up and also increase in outpatient clinic volume.

\section{Author's contribution}

Dr. Achyut N Pandey: Study concept and design

Dr. Parul Singh: Manuscript preparation

\section{Reference}

01. Quigley HA, Broman AT. The number of people with glaucoma worldwide in 2010 and 2020. Br J Ophthalmol. 2006;90(3)262-267. doi: 10.1136/bjo.2005.081224 [Crossref][PubMed] [Google Scholar]

02. Ramakrishna R, Nirmalan PK, Krishnada R, Thulasiraj RD, Tielsch JM, Katz J, et al. Glaucoma in a rural population of Southern India- the Aravind Comprehensive Eye Survey. Ophthalmol. 2003;110(8)1484-1490. doi: 10.1016/s01616420(03)00564-5 [Crossref][PubMed][Google Scholar]

03. Vijaya L, George R, Baskaran M, Arvind H, Raju $\mathrm{P}$, Ramesh SV, et al. Prevalence of primary open angle glaucoma in an urban south Indian population and comparison with a rural population, The Chennai Glaucoma Study. Ophthalmol. 2008;115;648-54. e1. doi: 10.1016/j.ophtha.2007.04.062 [Crossref][PubMed] [Google Scholar]

04. Tielsch JM, Katz J, Sommer A, Quigley HA, Javitt JC. Family history and risk of primary open angle glaucoma- The Baltimore Eye Survey. Arch Ophthalmol. 1994;112(1)69-73. doi:

10.1001/archopht.1994.01090130079022

[Crossref][PubMed][Google Scholar]

05. Leske MC, Connell AM, Wu SY, Nemesure B, Li $X$, Schachat A, Hennis A. Incidence of open-angle glaucoma- the Barbados Eye Studies, The Barbados Eye Studies Group. Arch Ophthalmol. 2001;119(1)89-95. [Crossref][PubMed][Google Scholar] 
06. Nemesure B, Leske MC, He Q, Mendell N. Analyses of reported family history of glaucoma- a preliminary investigation, The Barbados Eye Study Group. Ophthalmic Epidemiol. 1996;3(3)135-141. doi: $\quad 10.3109 / 09286589609080119$ [Crossref] [PubMed][Google Scholar]

07. Leighton DA. Survey of the first-degree relatives of glaucoma patients. Trans Ophthalmol Soc UK. 1976;96(1)28-32. [Crossref][PubMed][Google Scholar]

08. Wolfs RC, Klaver CC, Ramrattan RS, van Duijn CM, Hofman A, de Jong PT. Genetic risk of primary open-angle glaucoma, Population-based familial aggregation study. Arch Ophthalmol. 1998;116(12)1640-1645. doi: 10.1001/archopht.116.12.1640 [Crossref][PubMed] [Google Scholar]
09. Nguyen RL, Raja SC, Traboulsi EI. Screening relatives of patients with familial chronic open angle glaucoma. Ophthalmol. 2000;107(7)1294-1297. doi: 10.1016/s0161-6420(00)00156-1 [Crossref] [PubMed][Google Scholar]

10. Venkatesh R, Ramulu PY, Kavitha S, Sinha A, Wojciechowski R, Chan ES, Friedman DS. The Importance of Family History in Angle Closure Glaucoma. Invest Ophthalmol Visual Sci. 2012;53(14)4507. [Crossref][PubMed][Google Scholar]

11. Rajendrababu S, Gupta N, Vijayakumar B, Kumaragurupari R, Krishnadas SR. Screening First Degree Relatives of Persons with Primary Open Angle Glaucoma in India. J Curr Glaucoma Pract. 2014;8(3):07-112. doi: 10.5005\%2Fjp-journals10008-1172 [Crossref][PubMed][Google Scholar] 